Original Research Article

\title{
Efficacy of hydroxychloroquine as a potential antidiabetic drug
}

\author{
Mithun Kumar D.*, Laxminarayana Kamath, Narayana Reddy S.
}

Department of Pharmacology, Bangalore Medical College and Research Institute, Bengaluru, Karnataka, India

Received: 23 January 2017

Revised: 25 February 2017

Accepted: 27 February 2017

*Correspondence to:

Dr. Mithun Kumar D.,

Email:

mithunkumard@gmail.com

Copyright: $(\subset)$ the author(s), publisher and licensee Medip Academy. This is an openaccess article distributed under the terms of the Creative Commons Attribution NonCommercial License, which permits unrestricted noncommercial use, distribution, and reproduction in any medium, provided the original work is properly cited.

\section{ABSTRACT}

Background: India is the world's diabetic capital. Oral antidiabetic therapy is still incomplete. Prior studies have shown that hydroxychloroquine (HCQ), a commonly used antimalarial, anti-rheumatic drug reduces the risk of developing diabetes mellitus. It probably acts by decreasing insulin metabolism- a novel mechanism of action.

Methods: A systematic search was done in MEDLINE database with key words 'Type 2 Diabetes Mellitus', 'Hydroxychloroquine'. Articles assessing the antidiabetic efficacy of hydroxychloroquine were reviewed and their results summarized.

Results: With extensive literature search, we found out three RCTs and four Cohort studies assessing the efficacy of HCQ on glycaemic markers in patients with type 2 diabetes mellitus. Two randomized controlled trials done by Gerstein $\mathrm{H}$ C et al, Pareek A et al, comparing hydroxychloroquine with established antidiabetic drugs showed that there is significant reduction in glycaemic parameters with comparable similarity in both the groups (HbA1c: $0.91 \% \pm 0.4 \%$ ). Solomon et al in their study on patients with RA concluded that HCQ improved insulin sensitivity. Two cohort studies by Chen Y M et al and Wasko MCM et al respectively showed reduced incidence of diabetes mellitus in Systemic lupus erythematosus (Hazard ratio=0.26) and rheumatologic disease (relative risk=0.23) patients who received hydroxychloroquine. In a cohort study by Rekedal LR et al, HCQ reduced HbA1c by $0.66 \%$ compared to baseline in patients with RA. These studies also showed that hydroxychloroquine has favourable effect on lipid profile and good tolerability Conclusions: Hydroxychloroquine has a potential to enter antidiabetic armamentarium due to its efficacy and low toxicity profile. More studies are required to confirm this.

Keywords: Antidiabetic drugs, Hydroxychloroquine, Lipid profile, Novel

\section{INTRODUCTION}

Diabetes mellitus (DM) refers to "a group of common metabolic disorders that share the phenotype of hyperglycemia. Type $1 \mathrm{DM}$ is the result of complete or near-total insulin deficiency. Type $2 \mathrm{DM}$ is a heterogeneous group of disorders characterized by variable degrees of insulin resistance, impaired insulin secretion, and increased glucose production." Globally there were 422 million types 2 diabetics in 2014 out of which 69.2 million were from India which is projected to be 109 million by 2035 . These figures translate to a prevalence of $8.6 \%$ in Southeast Asia. ${ }^{2}$ Oral antidiabetic drugs metformin and sulfonylurea is the established initial therapy for type 2 DM. However the UKPDS study showed that sulfonylureas and metformin lose their efficacy with time. About $50 \%$ of the patients on sulfonylurea or metformin monotherapy require additional agents to maintain glycaemic control after 3 years. ${ }^{5}$ Even though thiazolidinediones, meglitinides, gliptins can be added to the therapeutic regimen of patients with secondary failure to initial therapy, they have limitations. Researchers are constantly in search of a new anti-diabetic drug which is safe as well as efficacious.

HCQ is a synthetic antimalarial drug commonly used in the treatment of autoimmune diseases like RA and SLE. ${ }^{6}$ HCQ use is associated with reduced DM incidence, reduction in HbA1c, blood glucose levels and improved 
lipid profile. ${ }^{7-11}$ HCQ most likely acts by reducing the lysosomal degradation of internalised insulin-insulin receptor complex. ${ }^{8,6}$ This is a novel mechanism of action in contrast to insulin secretagogue or insulin sensitizer action of other antidiabetic drugs. Also HCQ is relatively safe except for common adverse effects such as gastrointestinal discomfort and pruritus. ${ }^{6}$ In this context hydroxychloroquine (HCQ) holds promise as a new drug. With extensive literature search till date there were no systematic reviews on antidiabetic efficacy of HCQ. Considering all these facts the present review was undertaken.

\section{METHODS}

This systematic review was aimed at reviewing the evidence on the antidiabetic efficacy of HCQ.

\section{Criteria for selection of studies}

Randomised controlled trials (RCTs) and cohort studies were included in this review. Population included those with or at risk of type 2 diabetes mellitus. Studies compared hydroxychloroquine with another drug or no drug. Outcomes measured were incidence of type 2 diabetes mellitus, HbA1C, Insulin Sensitivity Index (ISI), Homeostatic Model for Assessment of Insulin resistance (HOMA-IR), LDL-C and HDL-C.

\section{Search methods for identifying the studies}

Electronic search was carried out using the keywordshydroxychloroquine, type 2 diabetes mellitus (T2DM). MEDLINE database was searched for studies. All the studies satisfying the inclusion criteria were considered for the review. The references of all the studies identified were inspected for more studies (Figure 1).

\section{Data collection and analysis}

Two authors independently read the full texts of the articles obtained and decided on the inclusion for review. A data extraction form was developed and used to extract all the relevant characteristics and outcome measurements from the studies. Both authors independently carried out the data extraction and recorded the data in the data extraction form. Any disagreements were settled by consensus.

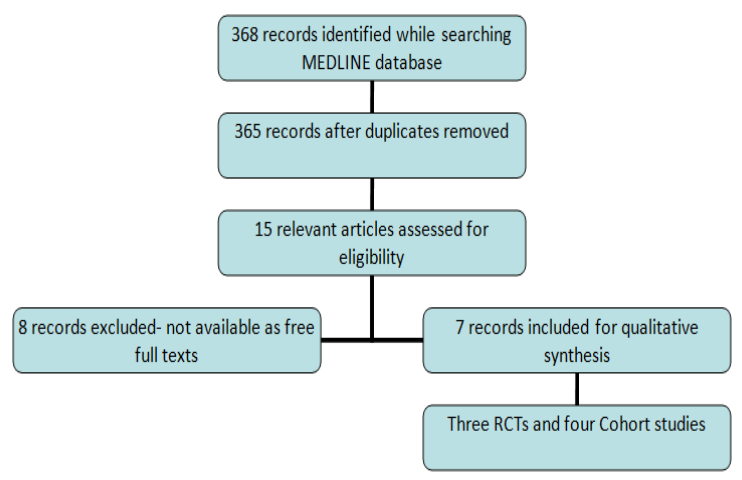

Figure 1: Flowchart of literature search and selection.

Risk of bias in the RCTs that were available as full texts was assessed by using Cochrane risk of bias tool. Diversity in the RCTs and cohort studies with respect the population studied, interventions/exposures and the outcomes measured made meta-analysis impractical.

\section{RESULTS}

\section{Description of the included studies}

Three RCTs were included for the review. 425 adults studied. Two studies compared HCQ with pioglitazone/placebo in uncontrolled diabetes mellitus. One study compared HCQ with placebo in non-diabetics with rheumatoid arthritis (RA) (Table 1, Table 2, Table $3)$.

Table 1: RCT 1.

\begin{tabular}{|c|c|c|c|c|c|}
\hline Authors & $\mathbf{N}$ & Population & Intervention & Outcome & Result \\
\hline \multirow{5}{*}{ Pareek A et al } & \multirow{5}{*}{267} & \multirow{5}{*}{$\begin{array}{l}\text { uncontrolled T2DM } \\
\text { HbA1c } 7.5-11.5 \\
\text { On SU+MF }\end{array}$} & \multirow{5}{*}{$\begin{array}{l}\text { HCQ } 400 \mathrm{mg} / \mathrm{d} \text { Vs. } \\
\text { Pioglitazone } 15 \mathrm{mg} / \mathrm{d} \text { (for } 24 \\
\text { weeks) }\end{array}$} & HbA1c (\%) & -0.87 vs $-0.9(p>0.05)$ \\
\hline & & & & FBS (mg/dl) & -14.2 vs $-18.3(p>0.05)$ \\
\hline & & & & PPBS & -31.8 vs $-24.5(p>0.05)$ \\
\hline & & & & $\mathrm{TC}$ & -14.3 vs $-1.16(p<0.05)$ \\
\hline & & & & LDL & -8.89 vs $+3.4(p<0.05)$ \\
\hline Risk of bias & & & & & \\
\hline
\end{tabular}

SU- Sulfonylurea, MF- Metformin, HbA1c- Glycated haemoglobin, FBS- Fasting Blood Sugar, PPBS- Postprandial Blood Sugar, TCTotal Cholesterol, LDL- Low Density Lipoprotein. '-', negative sign indicates reduction.

Four cohort studies were considered for review. Two studies involving 12,723 rheumatologic disease patients compared the incidence of T2DM in those who received HCQ with those who didn't.
One study compared methotrexate with HCQ in diabetics with rheumatologic diagnosis. Another study assessed the effect of HCQ on glycaemic and lipid parameters in obese non-diabetics (Table 4, Table 5, Table 6, Table 7). 
Table 2: RCT 2.

\begin{tabular}{|c|c|c|c|c|c|}
\hline Authors & $\mathbf{N}$ & Population & Intervention & Outcome & Result \\
\hline \multirow{5}{*}{$\begin{array}{l}\text { Solomon DH } \\
\text { et al }\end{array}$} & \multirow{5}{*}{23} & \multirow{5}{*}{$\begin{array}{l}\text { adults with RA } \\
\text { without DM }\end{array}$} & \multirow{5}{*}{$\begin{array}{l}\text { HCQ }(6.5 \mathrm{mg} / \mathrm{kg} / \mathrm{d}) \mathrm{vs} \text {. } \\
\text { placebo }(8+8 \text { weeks } \\
\text { cross over trial })\end{array}$} & ISI & $+0.4 \mathrm{vs}+0.14$ \\
\hline & & & & HOMA-IR & -0.3 vs -0.42 \\
\hline & & & & HOMA-B & -5.8 vs -6.8 \\
\hline & & & & TC & -12.7 vs $-3.0(\mathrm{p}<0.05)$ \\
\hline & & & & LDL & -12.4 vs $-4.2(p<0.05)$ \\
\hline Risk of bias & $\begin{array}{l}\text { Computer } \\
\text { generated } \\
\text { random } \\
\text { sequence }\end{array}$ & $\begin{array}{l}\text { Allocation not } \\
\text { concealed }\end{array}$ & double blind & $\begin{array}{l}\text { Outcomes- } \\
\text { ADRs not } \\
\text { reported in } \\
\text { detail }\end{array}$ & $\begin{array}{l}\text { Conflict of interest } \\
\text { declared }\end{array}$ \\
\hline
\end{tabular}

RA- Rheumatoid Arthritis, HCQ- Hydroxychloroquine, ISI- Insulin Sensitivity Index, HOMA-IR- Homeostatic Model Assessment of Insulin Resistance, HOMA-B- Homeostatic Model Assessment of Beta sell function. +, plus sign indicates increase and -, minus sign indicates reduction in the parameters.

Table 3: RCT 3.

\begin{tabular}{|c|c|c|c|c|c|}
\hline Authors & $\mathbf{N}$ & Population & Intervention & Outcome & Result \\
\hline \multirow{4}{*}{$\begin{array}{l}\text { Gerstein HC } \\
\text { et al }\end{array}$} & \multirow{4}{*}{$\begin{array}{l}135 \\
\mathrm{HCQ}=69 \\
\text { Placebo= } 66\end{array}$} & \multirow{4}{*}{$\begin{array}{l}35-80 \text { yrs } \\
\text { BMI }>25 \\
\text { Hbalc }>11 \% \\
\text { SU resistant }\end{array}$} & \multirow{4}{*}{$\begin{array}{l}\text { HCQ (max } \\
600 \mathrm{mg} / \mathrm{d}) \\
\text { vs. placebo for } \\
18 \text { months }\end{array}$} & $\begin{array}{l}\text { Withdrawal from study } \\
\text { due to inadequate } \\
\text { glycaemic control. }\end{array}$ & $69.6 \%$ vs $95.5 \%$ \\
\hline & & & & $\mathrm{HbA} 1 \mathrm{c} *$ & $\begin{array}{l}-0.96 \% \text { (vs placebo) } \\
(95 \% \text { CI }-0.24 \text { to }-1.81)\end{array}$ \\
\hline & & & & $\mathrm{TC}^{*}$ & $-13.92 \mathrm{mg} / \mathrm{dl}(\mathrm{p}<0.05)$ \\
\hline & & & & LDL* & $-16.63 \mathrm{mg} / \mathrm{dl}(\mathrm{p}<0.05)$ \\
\hline Risk of bias & $\begin{array}{l}\text { Computer } \\
\text { generated } \\
\text { random } \\
\text { sequence }\end{array}$ & $\begin{array}{l}\text { Allocation not } \\
\text { concealed }\end{array}$ & Double blind & $\begin{array}{l}\text { Nil incomplete } \\
\text { outcomes or selective } \\
\text { reporting, ADRs } \\
\text { reported }\end{array}$ & $\begin{array}{l}\text { Conflict of interest not } \\
\text { declared }\end{array}$ \\
\hline
\end{tabular}

*Values in low HbA1c (11\%-13.4\%) stratum at 9 months, HCQ- Hydroxychloroquine, BMI- Body Mass Index. HbA1c- Glycated haemoglobin, FBS- Fasting Blood Sugar, PPBS- Postprandial Blood Sugar, TC- Total Cholesterol, LDL- Low Density Lipoprotein.'-', negative sign indicates reduction.

Table 4: Cohort 1.

\begin{tabular}{|llllll|}
\hline Authors & N & Population & Exposure & Outcome & Result \\
Chen YM et al, & 8628 HCQ users, & SLE patients & Cumulative HCQ dose & incidence & HR=0.26 for \\
2015 & $\geq 129 \mathrm{~g}-5556(\mathrm{vs})$ & without RA, & $\geq 129 \mathrm{~g}$ vs $<129 \mathrm{~g}$. & patients taking \\
& $<129 \mathrm{~g}-1871$ & DM, Psoriasis & Mean follow up 5.6 yrs. & of DM & $\geq 129 \mathrm{~g} \mathrm{HCQ}$. \\
\hline
\end{tabular}

RA- Rheumatoid Arthritis, SLE- Systemic Lupus Erythematosus, HCQ- Hydroxychloroquine, DM- Diabetes mellitus, HR- Hazard Ratio.

Table 5: Cohort 2.

\begin{tabular}{|c|c|c|c|c|c|}
\hline Authors & $\mathbf{N}$ & Population & Exposure & Outcome & Result \\
\hline \multirow{4}{*}{ Mercer E et al } & \multirow{4}{*}{13} & \multirow{4}{*}{$\begin{array}{l}\text { obese adults without DM, } \\
\mathrm{BMI}>30\end{array}$} & \multirow{4}{*}{$\begin{array}{l}\mathrm{HCQ} 6.5 \mathrm{mg} / \mathrm{kg} / \\
\text { day for } 6 \text { weeks }\end{array}$} & \multirow{4}{*}{$\begin{array}{l}\text { ISI, HOMA- } \\
\text { IR, TC, LDL. }\end{array}$} & ISI: $+4.5(\mathrm{p}=0.04)$ \\
\hline & & & & & HOMA-IR: $-0.3(\mathrm{p}=0.09)$ \\
\hline & & & & & TC: $-7 \mathrm{mg} / \mathrm{dl}(\mathrm{p}<0.05)$ \\
\hline & & & & & LDL: $-6 \mathrm{mg} / \mathrm{dl}(\mathrm{p}<0.05)$ \\
\hline
\end{tabular}

HCQ- Hydroxychloroquine, RA- Rheumatoid Arthritis, ISI- Insulin Sensitivity Index, HOMA-IR- Homeostatic Model Assessment of Insulin Resistance, TC- Total Cholesterol, LDL- Low Density Lipoprotein. '-', negative sign indicates reduction and +, plus sign. Indicates increase

\section{Risk of bias assessment}

Two RCTs by Gerstein H C et al and Solomon D H et al were assessed for the risk of bias. There was high risk of selection bias in both the trials because of no mention of allocation concealment. High risk of reporting bias in the former and undeclared conflict of interest in the latter study was observed. There was low risk of bias in random sequence generation, blinding of participant/ assessors. 
Table 6: Cohort 3

\begin{tabular}{|c|c|c|c|c|c|}
\hline Authors & $\mathbf{N}$ & Population & Exposure & Outcome & Result \\
\hline Rekedal LR et al & $\begin{array}{l}82 \\
\mathrm{HCQ}=45 \\
\mathrm{MTX}=37\end{array}$ & $\begin{array}{l}\text { Rheumatic patients } \\
\text { with diabetes }\end{array}$ & HCQ vs MTX & $\begin{array}{l}\text { HbAlc measured at baseline } \\
\text { and again within } 12 \text { months }\end{array}$ & $\begin{array}{l}-0.66 \% \text { vs. }- \\
0.11 \%\end{array}$ \\
\hline
\end{tabular}

HCQ- Hydroxychloroquine, MTX- Methotrexate, HbA1c- Glycated haemoglobin. '-', negative sign indicates reduction.

Table 7: Cohort 4.

\begin{tabular}{|c|c|c|c|c|c|c|}
\hline Authors & Year & $\mathbf{N}$ & Population & Exposure & Outcome & Result \\
\hline \multirow{2}{*}{$\begin{array}{l}\text { Wasko } \\
\text { MCM et al }\end{array}$} & \multirow{2}{*}{2007} & \multirow{2}{*}{$\begin{array}{l}4095 \\
\mathrm{HCQ}=1808 \\
\text { (vs) no } \\
\mathrm{HCQ}=3097\end{array}$} & \multirow{2}{*}{$\begin{array}{l}\text { age }>16 \\
\text { Rheumatologic } \\
\text { diagnosis }\end{array}$} & \multirow{2}{*}{$\begin{array}{l}\text { HCQ vs } \\
\text { no HCQ }\end{array}$} & \multirow{2}{*}{$\begin{array}{l}\text { incidence of } \\
\text { DM }\end{array}$} & $\begin{array}{l}5.2 \text { vs } 8.9 \text { per } 1000 \mathrm{pt} \\
\text { yrs. }(\mathrm{p}<0.001)\end{array}$ \\
\hline & & & & & & $\begin{array}{l}\mathrm{RR}=0.23 \text { for HCQ use } \\
>4 \mathrm{yrs}\end{array}$ \\
\hline
\end{tabular}

\section{DISCUSSION}

Diabetes mellitus with a global prevalence of $8.6 \%$ is an important public health problem with long term complications like renal failure, blindness and coronary artery disease. The macrovasular and microvascular complications contribute to the morbidity and mortality due to diabetes mellitus. According to the $\mathrm{A}_{1}$ chieve study, the prevalence of complications in Indian population with type 2 diabetes mellitus were as followscardiovascular (23.6\%), neuropathy (24.6\%), nephropathy $(21.1 \%)$, retinopathy $(16.6 \%)$, foot ulcers $(5.1 \%) .^{3}$ The United Kingdom Prospective Diabetes study (UKPDS) showed that oral anti-diabetic drugs/ insulin (vs. diet alone) significantly reduce complications like retinopathy, nephropathy, and neuropathy. Each percentage point reduction in glycated haemoglobin reduced the risk of these complications by $35 \% .{ }^{4}$ Given the importance of diabetes as a global health problem, efforts to identify treatments that can manage this disorder have gained priority. Oral antidiabetic therapy is still incomplete.

Many below discussed studies have shown that antimalarials such as hydroxychloroquine, a long-standing safe and inexpensive treatment for autoimmune diseases such as rheumatoid arthritis and systemic lupus erythematosus, improve glucose tolerance and prevent diabetes mellitus with novel mechanism of action. ${ }^{7,12}$ So HCQ can be considered as a potential agent for the treatment of type 2 diabetes mellitus in general population. This is the first systematic review on antidiabetic efficacy of HCQ. The available studies were widely diverse not permitting meta-analysis. Hence each study was individually summarized.

Pareek A et al found HCQ to be as efficacious as pioglitazone in reducing glycaemic parameters $(p>0.05)$ and also superior to it in improving lipid parameters $(\mathrm{p}<0.05)$ in a 24 week RCT on diabetic patients. ${ }^{22}$ (Table 1). Another RCT by Gerstein et al on 135 patients with
T2DM resistant to sulfonylureas showed significant reduction of HbAlc $(-0.96 \%)$ with 18 months of HCQ without significant improvement in insulin resistance. This study supported the hypothesis of reduced insulin degradation as the possible mechanism of action of HCQ. $^{8}$ (Table 3). Contrary to this, A 16 weeks cross over RCT on 23 RA patients without T2DM by Solomon DH et al showed that 8 weeks of HCQ significantly reduced Total and LDL cholesterol $(\mathrm{p}<0.05)$ but had no effect on insulin resistance parameters. ${ }^{11}$ (Table 2). It is possible that the subject group studied did not have enough baseline insulin resistance to observe improvement with HCQ, duration of HCQ treatment was also short. ${ }^{11}$

When hydroxychloroquine was combined with insulin for the treatment of diabetes mellitus, glycated hemoglobin decreased significantly compared with patients receiving placebo, and the insulin dose had to be reduced by $30 \%$ in the hydroxychloroquine group. ${ }^{13}$ Moreover HCQ is relatively safe and well tolerated. ${ }^{6} \mathrm{~A}$ study by Mercer $\mathrm{E}$ et al on 13 obese non-diabetics showed significant improvement in insulin resistance with 6 weeks of HCQ. No concurrent evidence of improvement in inflammatory markers was observed (for example, CRP and IL-6 did not change). This argues for a direct effect of HCQ on insulin metabolism-reduced degradation or enhanced activity at the receptor level rather than an indirect effect through reduced inflammation. ${ }^{10}$ (Table 5) Another study by Quatraro et al showed decreased insulin requirements in diabetic patients receiving $\mathrm{HCQ}$ with the $\mathrm{C}$ peptide levels remaining the same. ${ }^{16}$ Inhibitory effect on insulin metabolism in animal models and in vitro studies have also been documented with evidence of decreased degradation and intracellular accumulation. ${ }^{14,15,17}$

Chloroquine analogues have plasma lipid-lowering effects in diabetes mellitus, RA, SLE and dyslipidaemia that are therapeutically relevant due to the increased risks of premature atherosclerosis in these diseases. Mechanisms responsible for altered lipid profiles with chloroquine analogue treatment include a significant 
increase in lipid clearance rate and up-regulation of LDL receptors. $^{6,8,10,11,20,22}$ In this context chloroquine is effective as both hypolipidaemic and antidiabetic drug.

In rheumatic disease patients, systemic inflammation appears to be responsible for insulin resistance through elevated levels of TNF $\alpha$ and IL- $6 .{ }^{18}$ The glycaemic improvement afforded by HCQ is seen in diabetics as well as in rheumatologic disease patients indicating a mechanism other than suppression of inflammation. In addition HCQ was superior to methotrexate in reducing the $\mathrm{HbA} 1 \mathrm{c}(-0.66 \%$ vs $0.11 \%)$ among RA patients in a retrospective cohort study again highlighting a mechanism other than anti-inflammatory action. ${ }^{19}$ (Table $6)$.

Two cohort studies by Chen YM et al and Wasko M et al found reduced risk of developing T2DM in patients with rheumatologic diseases in hydroxychloroquine users compared with nonusers. Risk reduction was proportional to dose and duration of HCQ administration. Risk is decreased by $74 \%-77 \%$ with $\geq 129$ g cumulative dose of HCQ and/ or 4 years of HCQ use., ${ }^{72}$ (Table 4, Table 7).

HCQ is the least toxic of the 4 amino quinolines, and perhaps the least toxic of DMARDs. Patients given HCQ do not need any specific laboratory monitoring but do need periodic ophthalmic checks for early signs of reversible retinal toxicity. HCQ is relatively safe except for the rare adverse effects like retinopathy, neuromyopathy, and myopathy. Most common adverse effects are gastrointestinal discomfort and pruritus. ${ }^{6}$ other side effects include nausea, epigastric pain, myopathy, haemolytic anaemia and skin pigmentation. So it has been suggested that formulations of HCQ containing Senantiomer may reduce the risk of retinopathy and skin pigmentation. $^{21}$

Because of the antidiabetic efficacy, relative safety and low cost of hydroxychloroquine, it emerges as a therapeutic option for type 2 diabetic mellitus. With further good quality RCTs, a more useful and precise result can be obtained from systematic reviews and metaanalysis.

\section{CONCLUSION}

HCQ is comparable with pioglitazone in improving glycaemic control in T2DM. Reduced incidence of T2DM is seen in HCQ treated RA and SLE patients. In addition trials have consistently shown significant reduction in total cholesterol and LDL-cholesterol levels. Further studies on the mechanism and efficacy of different doses of this drug in patients with diabetes who are on different therapeutic regimens, with different degrees of hyperglycemia are clearly needed to include HCQ in therapeutic armamentarium of type 2 diabetes mellitus.

Funding: No funding sources Conflict of interest: None declared
Ethical approval: The study was approved by the Institutional Ethics Committee

\section{REFERENCES}

1. Powers AC. Diabetes Mellitus. In: Longo DL, Fauci AS, Kasper DL, Hauser SL, Jameson JL, Loscalzo J, editors. Harrison's Principles of Internal Medicine. $18^{\text {th }}$ Ed. New York: McGraw-Hill; 2012:2968.

2. World Health Organization. Global Report on Diabetes. ISBN. 2016;978. Available from: http://www.who.int/about/licensing/\%5Cnhttp://apps. who.int/iris/bitstream/10665/204871/1/97892415652 57_eng.pdf.

3. Mohan V, Shah S, Saboo B. Current glycemic status and diabetes related complications among type 2 diabetes patients in India: data from the A1chieve study. J Assoc Physicians India. 2013;61(1):12-5.

4. Genuth S, Eastman R, Kahn R, Klein R. Others. Implications of the United Kingdom prospective diabetes study. Clin Diabetes. 1999;17(1):5.

5. Turner RC, Cull CA, Frighi V, Holman RR. For the UK Prospective Diabetes Study (UKPDS) Group. Glycemic control with diet, sulfonylurea, metformin, or insulin in patients with type 2 diabetes mellitus: Progressive requirement for multiple therapies (ukpds 49). JAMA. 1999;281(21):2005-12.

6. Al-Bari MA. Chloroquine analogues in drug discovery: new directions of uses, mechanisms of actions and toxic manifestations from malaria to multifarious diseases. Journal of Antimicrobial Chemotherapy. 2015;70(6):1608-21.

7. Wasko MCM, Hubert HB, Lingala VB, Elliott JR, Luggen ME, Fries JF, et al. Hydroxychloroquine and risk of diabetes in patients with rheumatoid arthritis. Jama. 2007;298(2):187-93.

8. Gerstein HC, Thorpe KE, Taylor DW, Haynes RB. The effectiveness of hydroxychloroquine in patients with type 2 diabetes mellitus who are refractory to sulfonylureas- a randomized trial. Diabetes Res Clin Pract. 2002;55(3):209-19.

9. Winter EM, Schrander-van der Meer A, EustatiaRutten C, Janssen M. Hydroxychloroquine as a glucose lowering drug. Case Rep. 2011.

10. Mercer E, Rekedal L, Garg R, Lu B, Massarotti EM, Solomon DH. Hydroxychloroquine improves insulin sensitivity in obese non-diabetic individuals. Arthritis Res Ther. 2012;14(3):1.

11. Solomon DH, Garg R, Lu B, Todd DJ, Mercer E, Norton $\mathrm{T}$, et al. Effect of hydroxychloroquine on insulin sensitivity and lipid parameters in rheumatoid arthritis patients without diabetes mellitus: a randomized, blinded crossover trial. Arthritis care \& research. 2014;66(8):1246-51.

12. Chen Y-M, Lin C-H, Lan T-H, Chen H-H, Chang S$\mathrm{N}$, Chen $\mathrm{Y}-\mathrm{H}$, et al. Hydroxychloroquine reduces risk of incident diabetes mellitus in lupus patients in a dose-dependent manner: a population-based cohort study. Rheumatology. 2015;54(7):1244-9. 
13. Krentz AJ, Bailey CJ. Oral antidiabetic agents. Drugs. 2005;65(3):385-411.

14. Emami J, Pasutto FM, Mercer JR, Jamali F. Inhibition of insulin metabolism by hydroxychloroquine and its enantiomers in cytosolic fraction of liver homogenates from healthy and diabetic rats. Life Sci. 1999;64(5):325-35.

15. Cynober L, Aussel C, Vaubourdolle M, Agneray J, Ekindjian OG. Modulation of insulin action on 2deoxyglucose uptake by chloroquine in chick embryo fibroblasts. Diabetes. 1987;36(1):27-32.

16. Quatraro A, Consoli G, Magno M, Caretta F, Nardozza A, Ceriello A, et al. Hydroxychloroquine in decompensated, treatment-refractory noninsulindependent diabetes mellitus. A new job for an old drug? Ann Intern Med. 1990;112(9):678-81.

17. Garcia-Webb P, Bonser AM. Insulin binding and degradation in isolated hepatocytes from streptozotocin injected rats. Biochem Biophys Res Commun. 1985;128(2):487-93.

18. Chung CP, Oeser A, Solus JF, Gebretsadik T, Shintani A, Avalos I, et al. Inflammation associated insulin resistance: Differential effects in rheumatoid arthritis and systemic lupus erythematosus define potential mechanisms. Arthritis Rheum. 2008;58(7):2105-12.
19. Rekedal LR, Massarotti E, Garg R, Bhatia R, Gleeson $\mathrm{T}$, Lu B, et al. Changes in glycosylated hemoglobin after initiation of hydroxychloroquine or methotrexate treatment in diabetes patients with rheumatic diseases: Changes in HbA 1c with HCQ or MTX. Arthritis Rheum. 2010;62(12):3569-73.

20. Sharma TS, Wasko MCM, Tang X, Vedamurthy D, Yan X, Cote J, et al. Hydroxychloroquine use is associated with decreased incident cardiovascular events in rheumatoid arthritis patients. J Am Heart Assoc. 2016;5(1):2867.

21. Thabah M, Ravindran V. Antimalarials in rheumatology: Expanding therapeutic armamentarium. Indian J Rheumatol. 2015;10(2):512.

22. Pareek A, Chandurkar N, Thomas N, Viswanathan V, Deshpande A, Gupta OP, et al. Efficacy and safety of hydroxychloroquine in the treatment of type 2 diabetes mellitus: a double blind, randomized comparison with pioglitazone. Curr Med Res Opin. $2014 \mathrm{Jul} ; 30(7): 1257-66$.

Cite this article as: Kumar MD, Kamath L, Reddy NS. Efficacy of hydroxychloroquine as a potential antidiabetic drug. Int $\mathbf{J}$ Basic Clin Pharmacol 2017;6:895-900. 